University of Nebraska - Lincoln

DigitalCommons@University of Nebraska - Lincoln

USDA Forest Service / UNL Faculty Publications U.S. Department of Agriculture: Forest Service -National Agroforestry Center

2011

Thermogravimetric analysis of forest understory grasses

Thomas Elder

USDA-Forest Service

John S. Kush

Auburn University

Sharon M. Hermann

Auburn University

Follow this and additional works at: https://digitalcommons.unl.edu/usdafsfacpub

Part of the Forest Sciences Commons

Elder, Thomas; Kush, John S.; and Hermann, Sharon M., "Thermogravimetric analysis of forest understory grasses" (2011). USDA Forest Service / UNL Faculty Publications. 157.

https://digitalcommons.unl.edu/usdafsfacpub/157

This Article is brought to you for free and open access by the U.S. Department of Agriculture: Forest Service -National Agroforestry Center at DigitalCommons@University of Nebraska - Lincoln. It has been accepted for inclusion in USDA Forest Service / UNL Faculty Publications by an authorized administrator of DigitalCommons@University of Nebraska - Lincoln. 


\title{
Thermogravimetric analysis of forest understory grasses
}

\author{
Thomas Elder ${ }^{\mathrm{a}, *}$, John S. Kush ${ }^{\mathrm{b}}$, Sharon M. Hermann ${ }^{\mathrm{c}}$ \\ a USDA-Forest Service, Southern Research Station, 2500 Shreveport Highway, Pineville, LA 71360, USA \\ ${ }^{\mathrm{b}}$ School of Forestry and Wildlife Sciences, Auburn University, Auburn, AL 36849, USA \\ ${ }^{\mathrm{c}}$ Department of Biological Sciences, Auburn University, Auburn, AL 36849, USA
}

\section{A R T I C L E I N F O}

\section{Article history:}

Received 14 July 2010

Received in revised form

29 September 2010

Accepted 5 October 2010

Available online 15 October 2010

\section{Keywords:}

Thermogravimetric analysis

Grasses

Activation energy

Forest

Fire

\begin{abstract}
A B S T R A C T
Forest understory grasses are of significance in the initiation, establishment and maintenance of fire whether used as a management tool or when occurring as wildfire. The fundamental thermal properties of such grasses are critical to their behavior in fire situations and have been investigated in the current work by the application of thermogravimetric analysis (TGA). TGA was performed in nitrogen and air, over a range of heating rates, allowing for the determination of activation energies and temperatures associated with the degradation of hemicelluloses and cellulose. Of particular interest is the behavior of Imperata cylindrica (cogongrass) an invasive species in the southern United States, which has been found to result in elevated temperatures during fires in forested ecosystems. The results from TGA for this species are in accord with these observations from the field.
\end{abstract}

\section{Introduction}

Fire in a forested environment can have a number of consequences, some of which are destructive while others are biologically essential or important management tools. Among the factors that control fire behavior are the combustion properties of the fuels, exerting considerable influence on fire initiation, establishment and propagation.

Forest fuels have been studied at various levels of organization, providing a range of information on their combustion. Large scale studies involving the application of laboratory burners for the evaluation of flame height have been reported for understory tree species [1] and pine needles [2]. Also using samples of relatively large size $(\sim 100 \mathrm{~mm} \times 100 \mathrm{~mm})$, cone calorimetry has been extensively used for the determination of heat release rate, mass loss rate, time to ignition, and effective heat of combustion. White et al. [3] report results from cone calorimetry on landscaping plants from California, a number of tree and understory species from Colorado, and native and invasive plants from the northeastern United States. No significant differences were detected between the species, but high and low flammability species were identified. Weise et al. [4] working with 10 ornamental species reported heat release rates of $49-331 \mathrm{~kW} \mathrm{~m}^{-2}$ for dry material and correlated these results

\footnotetext{
* Corresponding author. Tel.: +1 318473 7008; fax: +1 3184737246 .

E-mail addresses: telder@fs.fed.us (T. Elder), kushjoh@auburn.edu (J.S. Kush), hermasm@auburn.edu (S.M. Hermann).
}

with an intermediate scale calorimeter. Studying a large number of native and invasive plants [5], cone calorimetry results indicated that the heat of combustion was somewhat lower for invasives.

At a more fundamental level, thermogravimetric analysis (TGA) and differential scanning calorimetry (DSC) have been used to evaluate basic characteristics of thermal degradation on the chemical kinetics of reactions at elevated temperatures. These techniques have been applied to herbaceous materials in general [6-10] and forest fuels in particular [11-15].

TGA results for a number of Mediterranean scrub species [15] indicate a typical multi-step process with onset temperatures ranging from 540 to $572 \mathrm{~K}$ and offset temperatures for cellulose of $634-684 \mathrm{~K}$, increasing as would be predicted with heating rate. The results allowed for the classification of materials into groups based on weight loss at a given temperature, with Erica arborea and Pinus pinaster exhibiting greater weight loss percentage than Cistus monspeliensis and Arbutus unedo.

Rovira et al. [14] examined forest litter from four European pine forests, at six stages of decomposition. Two peaks were found in the DTGA (differential thermogravimetric analysis) plots, which shift to lower temperatures with degradation. Energy storage is reported to increase with decomposition, attributed to an increase in the recalcitrance of the remaining organic matter.

Ignition and combustion, as studied by TGA has been reported by Liodakis et al. [13] for Pinus halepensis, Pistacia lentiscus, Quercus coccifera, Cistus incanus, A. unedo and leaf litter. The authors defined the ignition temperature as the onset of gas-phase combustion, 

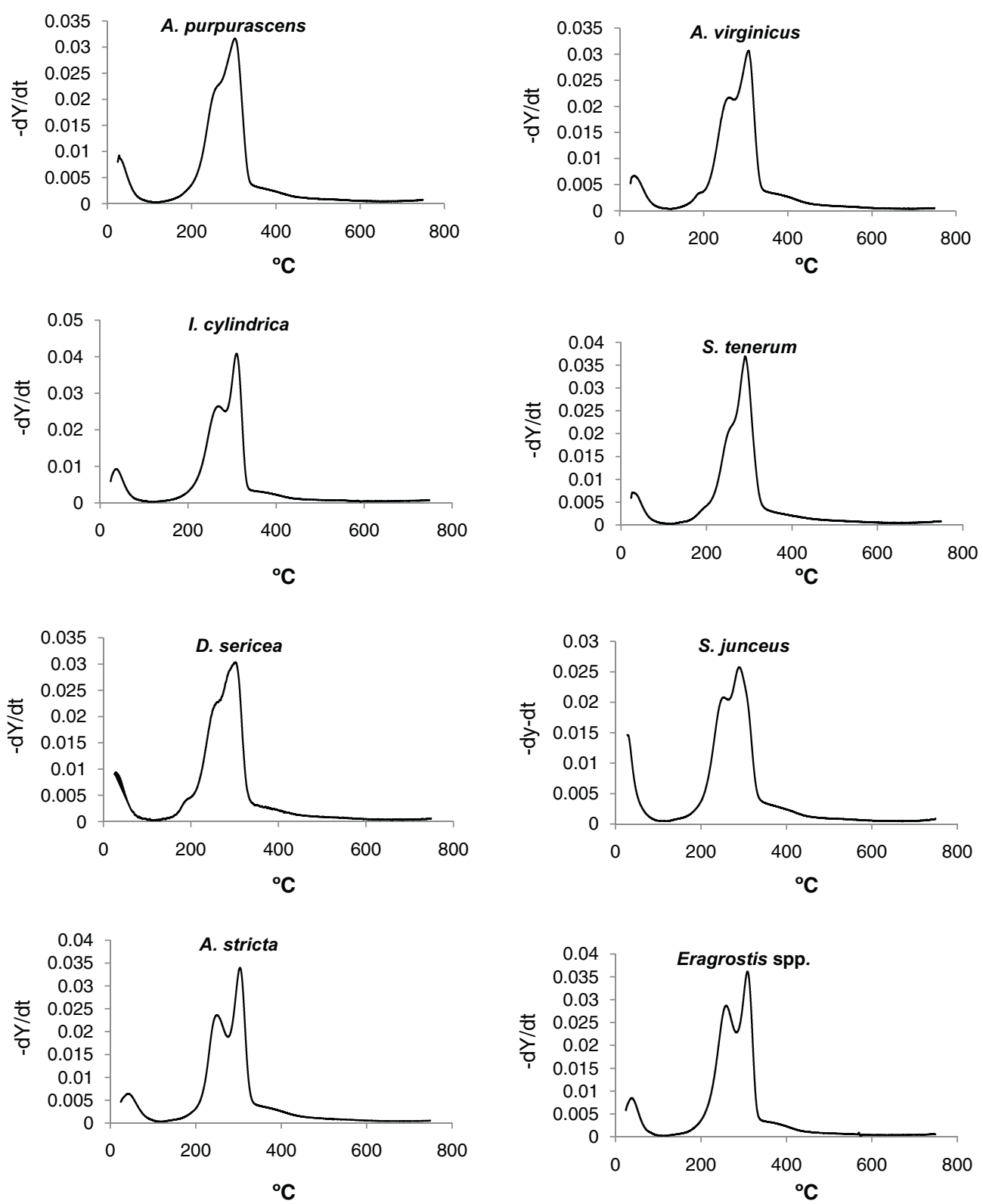

Fig. 1. DTGA results in nitrogen.

which was reported to range from $459 \mathrm{~K}$ to $476 \mathrm{~K}$, with the forest litter sample representing the highest value. The maximum weight loss rate as measured from the DTGA results, proposed to be directly related to combustibility exhibited considerable variability, with $P$. halepensis having the highest value.

The purpose of the current work is to examine the degradation temperatures and kinetic parameters of a number of understory grasses found in the longleaf pine (Pinus palustris) ecosystem of the southern United States, by the application of TGA. The longleaf pine ecosystem is of significance because at the time of European settlement it was a dominant tree species accounting for over $2 / 3$ of the southeastern United States. Furthermore, these forests that were historically maintained by fire have been reduced to 3\% of the original area, much of which currently receives inadequate fire. As such, this forest type has been described as one of the most endangered ecosystems in the United States [16]. Longleaf pine management and restoration are dependent on periodic fire events, and as such the understory species through which the fires are initiated and propagated are of critical importance. TGA experiments were done in nitrogen and air, to determine thermal behavior associated with both pyrolysis and combustion, respectively.

\section{Methods and materials}

\subsection{Sample collection and preparation}

The grass species to be evaluated in the current work are, Danthonia sericea, Aristida purpurascens, Schizachryrium tenerum, Sporobolus junceus, Andropogon virginicus, Aristida stricta, Imperata cylindrica and Eragrostis spp. Samples were collected in the latewinter/early spring of 2010 in Alabama and Florida. The samples were dried at $40^{\circ} \mathrm{C}$ for $4 \mathrm{~h}$ and ground on a Wiley mill to pass a 20 mesh screen. The mild drying conditions were selected to avoid any thermal degradation as a result of this initial processing step. After grinding the samples were stored under ambient conditions prior to analysis. This gave samples with reasonably consistent moisture contents (air-dry basis), which at the time of testing were D. sericea (6.2\%), A. purpurascens (6.5\%), S. tenerum (5.8\%), S. junceus 

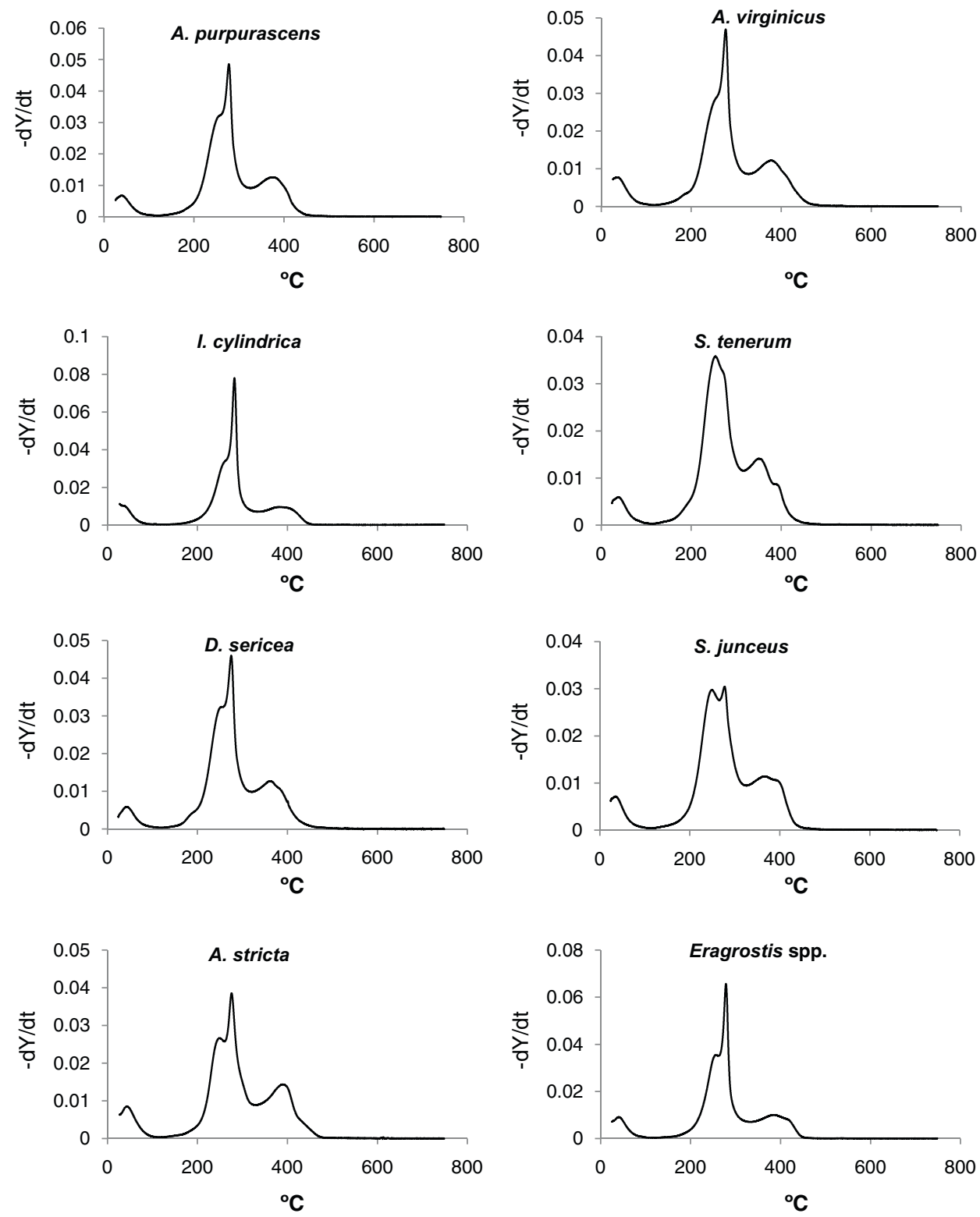

Fig. 2. DTGA results in air.

(6.2\%), A. virginicus (6.9\%), A. stricta (7.4\%), I. cylindrica (8.0\%) and Eragrostis spp (7.5\%).

\subsection{Thermogravimetric analysis (TGA)}

Analyses were performed in open, platinum sample holders, using a TA-Instruments Q-50 thermogravimetric analysis system. Samples of approximately $20 \mathrm{mg}$ were heated from ambient $\left(\sim 25^{\circ} \mathrm{C}\right)$ to $750^{\circ} \mathrm{C}$ at $\beta$ values $2.5,5,10$ and $15^{\circ} \mathrm{C} \mathrm{min}^{-1}$, in nitrogen and air with a gas flow rate of $60 \mathrm{~mL} \mathrm{~min}^{-1}$. Temperatures associated with the onset of hemicellulose degradation $\left(T_{\text {onset }(\mathrm{HC})}\right)$, the peak of hemicellulose degradation $\left(T_{\text {shoulder }}\right)$, the point of maximum devolatilization, primarily concerned with cellulose degradation $\left(T_{\text {peak }}\right)$, and the point at which lignin degradation is initiated $\left(T_{\text {offset(C) }}\right)$ were determined as described by Grønli et al. [17]. $T_{\text {onset( } \mathrm{HC})}$ is determined graphically by extrapolating the slope of the $-\mathrm{d} Y / \mathrm{d} t$ curve at the first maximum of the $-\mathrm{d}^{2} Y / \mathrm{d} t^{2}$ curve to zero on the $Y$-axis. $T_{\text {shoulder }}$ is identified as the value on the $-\mathrm{d} Y / \mathrm{d} t$ curve at the first minimum of the $-\mathrm{d}^{2} Y / \mathrm{d} t^{2}$ curve. $T_{\text {peak }}$ is the maximum of the $-\mathrm{d} Y / \mathrm{d} t$ curve. $T_{\text {offset(C) }}$ is determined by extrapolating the slope of the $-\mathrm{d} Y / \mathrm{d} t$ curve at the second minimum of the $-\mathrm{d}^{2} Y / \mathrm{d} t^{2}$ curve to zero on the $Y$-axis. In addition the residual weight percentages associated with $T_{\text {shoulder }}\left(Y_{\text {shoulder }}\right), T_{\text {peak }}\left(Y_{\text {peak }}\right)$, and at $500{ }^{\circ} \mathrm{C}\left(Y_{500}{ }^{\circ} \mathrm{C}\right)$ were determined in accordance with Grønli et al. [17].

To facilitate comparisons between the various degradation temperatures, the method of Yao et al. [9] was adopted in which each heating rate $(\beta)$ is extrapolated to $\beta=0$. This technique is based on the known linear increase in these temperatures as a function of heating rate. The data for a given thermal parameter $\left(T_{i}\right)$ is fitted to $T_{i}=a \beta+b$, where the intercept $b$ is the value for $T_{i}$ at $\beta=0$.

The activation energy $\left(E_{a}, \mathrm{~kJ} \mathrm{~mol}^{-1}\right)$ was calculated using the isoconversional method of Flynn and Wall [18] as implemented in ASTM E-1641-07 [19]. In this procedure, runs are performed with a minimum of three different heating rates. For a given level of conversion, the absolute temperature is recorded and a plot of the logarithm of the heating rate $(\beta)$ and reciprocal of the temperature in degrees kelvin is constructed, resulting in a linear relationship. Through an iterative procedure, the activation energy is calculated from the slope of the line. 
$\mathrm{T}_{\text {onset }(\mathrm{HC})}$
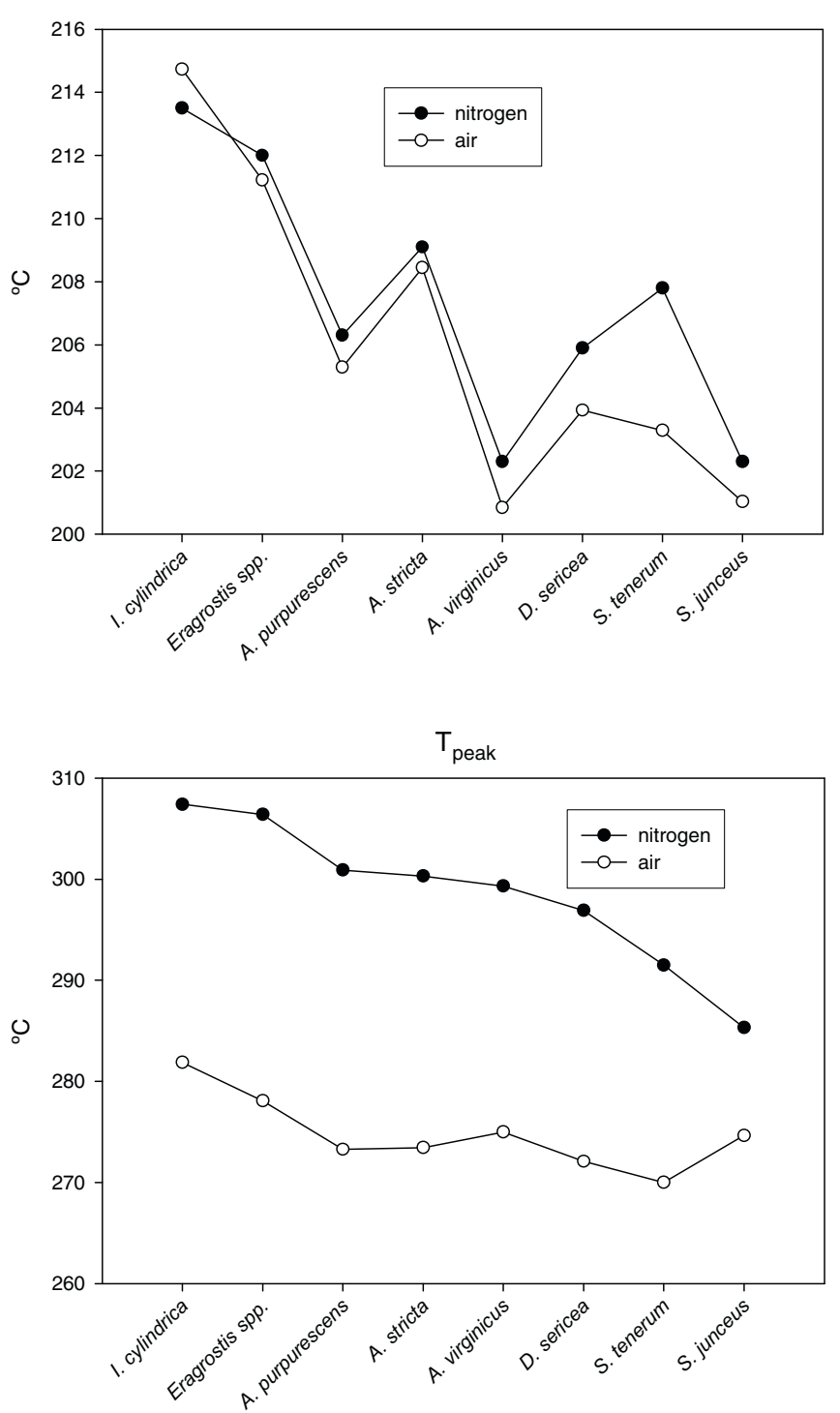
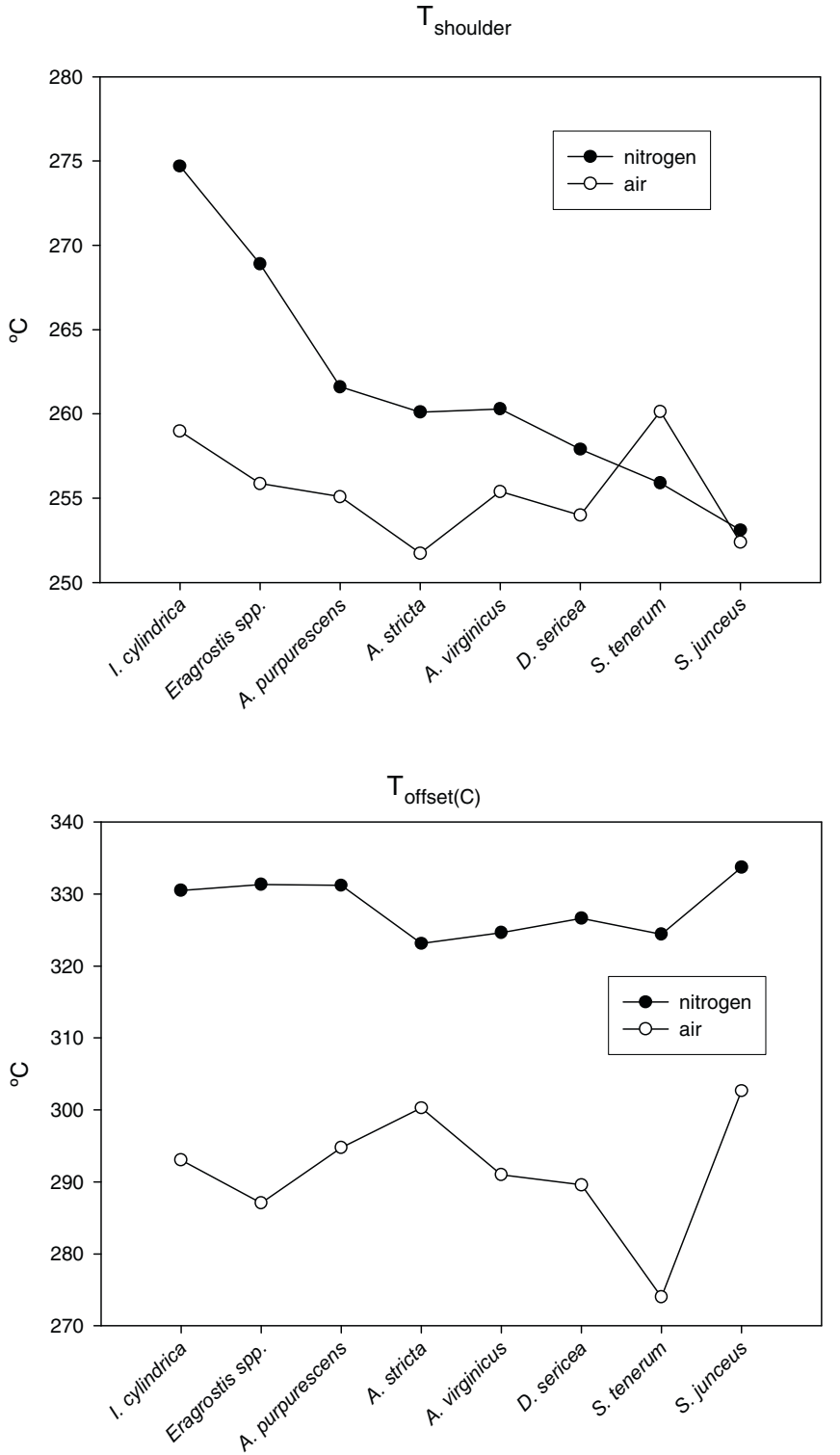

Fig. 3. $T_{\text {onset(HC)}}, T_{\text {shoulder }}, T_{\text {peak }}, T_{\text {offset(C) }}$ results in nitrogen and air.

\section{Results and discussion}

\subsection{DTGA results}

DTGA curves for the degradation of the grasses in nitrogen and air are shown in Figs. 1 and 2, respectively.

\subsubsection{DTGA results in nitrogen}

Fig. 1 shows the results for degradation in nitrogen at a heating rate of $2.5^{\circ} \mathrm{C} \mathrm{min}^{-1}$. The typical pattern of two peaks, with varying degrees of resolution can be observed. The shoulder at about $270^{\circ} \mathrm{C}$ is due to the overlap in decomposition temperature between cellulose and hemicellulose. Differing levels of separation have been reported for wood [17] with the shoulder being more distinct for hardwoods than softwoods. Yao et al. [9] found a similar pattern for wood and also observed such differences among agricultural fibers. In the current results A. purpurascens, S. tenerum, S. junceus and $D$. sericea exhibit relatively low resolution, while the peaks for A. stricta, I. cylindrica, A. viginicus and Eragrostis spp. are more completely separated. The different degrees of peak separation are due to changes in the rate of weight loss with temperature. In the curves which exhibit lower resolution, there is more overlap between the hemicellulose and cellulose peaks and a more uniform rate of weight loss is maintained. The results with greater resolution correspond to a marked slowing of the weight loss rate between the peaks for hemicellulose and cellulose. Such behavior could be due to different levels of cellulose crystallinity or association between hemicellulose and cellulose (Sunkyu Park, personal communication). It can also be seen that $A$. virginicus, $S$. tenerum and $D$. sericea have small shoulders $\sim 200^{\circ} \mathrm{C}$ which is consistent with the volatilization of extractives [17].

\subsubsection{DTGA results in air}

Fig. 2 shows the results for degradation in air at a heating rate of $2.5^{\circ} \mathrm{C} \mathrm{min}^{-1}$. While somewhat sharper, the general form of the curves is similar to the results in nitrogen, with a shoulder at $\sim 250^{\circ} \mathrm{C}$ and major peak at $\sim 300^{\circ} \mathrm{C}$. In addition, as is typically seen in lignocellulosic samples heated in air, a reasonably well resolved peak occurs at $\sim 400^{\circ} \mathrm{C}$, assigned to char oxidation [20]. As with the results in nitrogen, there are differences in the resolution of 

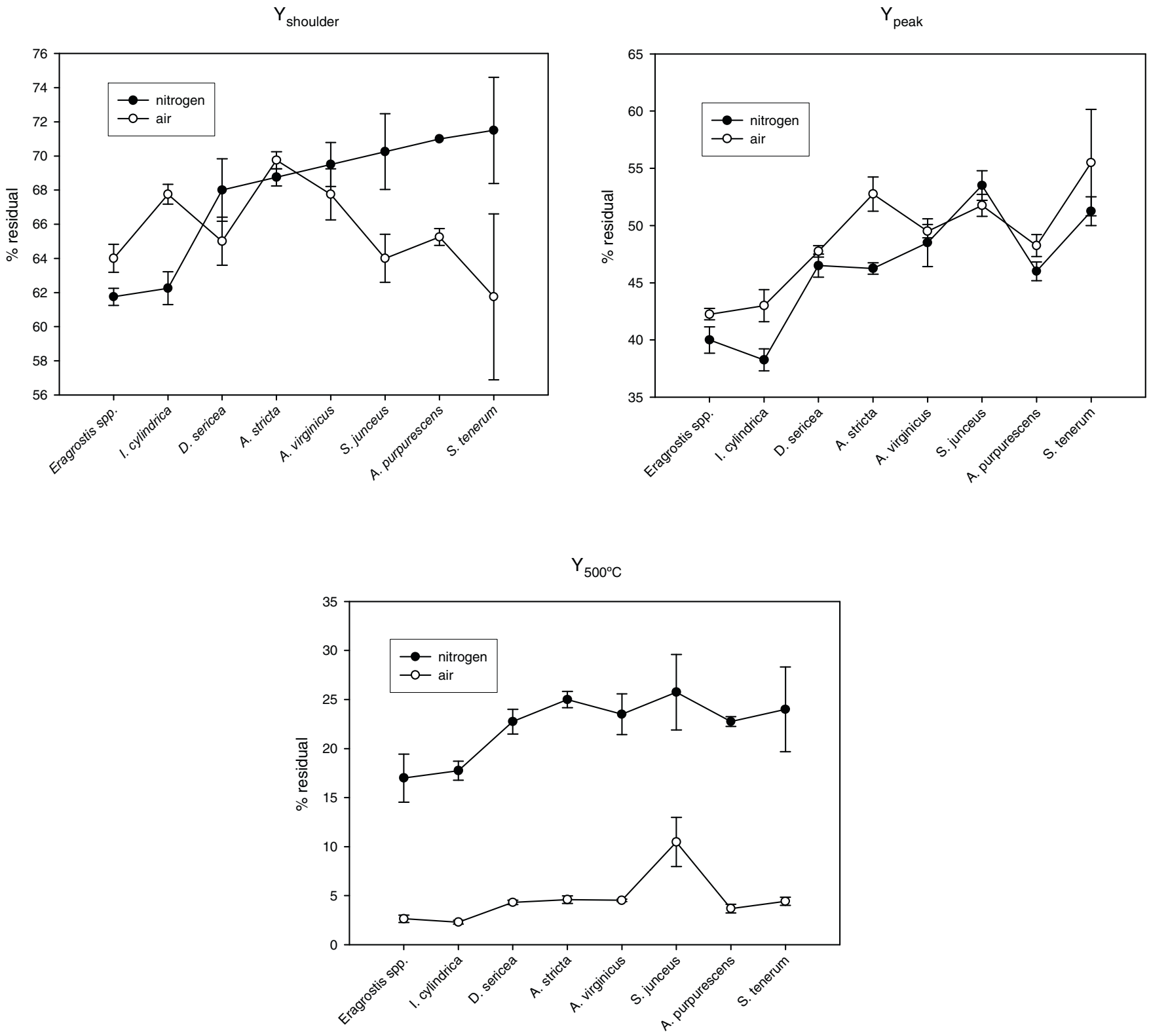

Fig. 4. $Y_{\text {shoulder }}, Y_{\text {peak }}, Y_{500}{ }^{\circ} \mathrm{C}$ results in nitrogen and air.

the hemicellulose and cellulose peaks, with A. stricta, D. sericea and Eragrostis spp. exhibiting higher degrees of separation. It is interesting to note the substantial differences in degradation patterns for S. tenerum and S. junceus. The former is very poorly resolved with the initial peak, which would normally just be a shoulder actually having the higher magnitude. In addition, it appears as if there are multiple, poorly resolved high temperature peaks beginning at about $350^{\circ} \mathrm{C}$. In contrast, S. junceus shows reasonable resolution, but the initial hemicellulose peak is quite large, obscuring the cellulose peak. Based on these data, S. tenerum and S. junceus appear to have markedly different thermal degradation behaviors under air than the other grasses examined.

\subsection{Temperature results}

The values for $T_{\text {onset(HC) }}, T_{\text {shoulder }}, T_{\text {peak }}$ and $T_{\text {offset(C) }}$ extrapolated to $\beta=0$ for all species in both nitrogen and air are shown in Fig. 3. In general, these degradations occur at higher tempera- tures under nitrogen than air. It can also be seen that for all points except $T_{\text {offset(C) }}$, the highest temperatures are associated with $I$. cylindrica. These observations, particularly $T_{\text {onset(HC) }}$ taken as a measure of ignition temperature $[13,15]$, are consistent with reports that the presence of $I$. cylindrica in forest understory can result in fires with elevated temperatures [21]. It is also interesting to note that the degradation temperatures for Eragrostis spp. are only slightly lower than for I. cylindrica, and both of these grasses are exotics in locations in which they were collected. Parenthetically, since these values are derived from the DTGA curves, the results reported for $S$. tenerum in air should be viewed with a considerable degree of skepticism, due to the irregularity observed for this species of grass under these conditions (Fig. 2). An evaluation of the literature shows that $T_{\text {onset(HC) }}$ values in the current work are slightly lower than those reported by Jeguirim and Trouvé [7] and Leroy et al. [15]. The $T_{\text {peak }}$ values are somewhat lower than those Jeguirim and Trouvé [7] while agreeing fairly well with Leroy et al. [15] and Munir et al. [8]. The latter paper also reports that $T_{\text {peak }}$ 

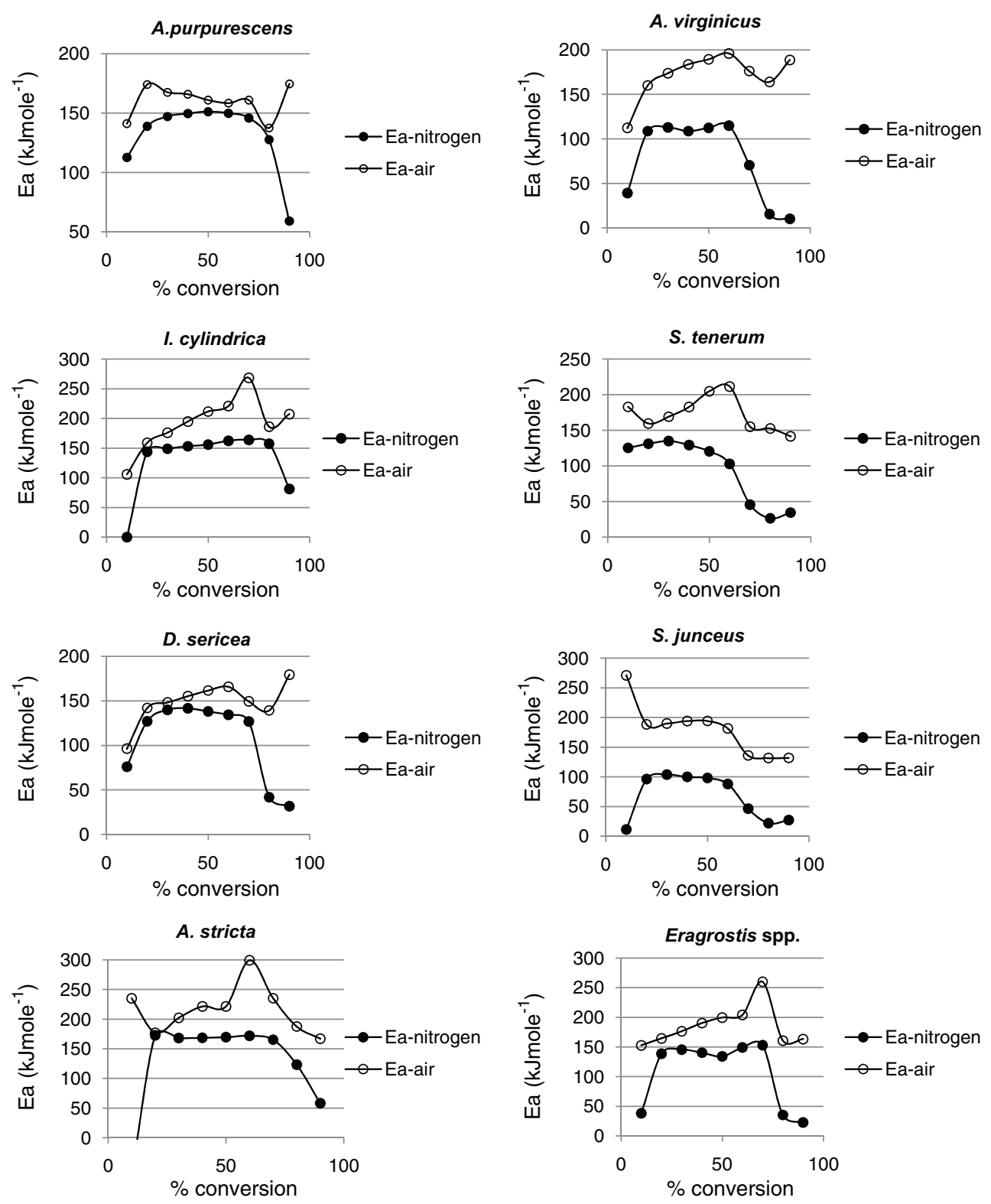

Fig. 5. Activation energy distributions in nitrogen and air.

in air is lowered $\sim 30-50^{\circ} \mathrm{C}$ as compared to nitrogen, which is in agreement with the current results.

\subsection{Residual weight percentages}

The results for the residual weight percentages associated with $T_{\text {shoulder }}\left(Y_{\text {shoulder }}\right), T_{\text {peak }}\left(Y_{\text {peak }}\right)$, and at $500{ }^{\circ} \mathrm{C}\left(Y_{500}{ }^{\circ} \mathrm{C}\right)$ are as shown in Fig. 4. As might be expected from the preceding temperature results, Eragrostis spp. and I. cylindrica exhibit the highest levels of degradation as measured by residual weight percentage. This is quite obvious for the $Y_{\text {shoulder }}$ values under nitrogen in which these two species have lost considerably more weight than the other grasses at this point. The introduction of air however, leads to more mixed results, perhaps indicating different chemistries associated with oxidation at lower temperatures. The $Y_{\text {peak }}$ and $Y_{500}{ }^{\circ} \mathrm{C}$ values for air and nitrogen roughly parallel each other, again with Eragrostis spp. and I. cylindrica having lost the largest weight percentages. The $Y_{500}{ }^{\circ} \mathrm{C}$ results indicate that $S$. junceus has much higher ash content than the other species under examination.

\subsection{Activation energy distributions}

The distribution of activation energies $\left(E_{a}\right)$ in $\mathrm{kJ} \mathrm{mol}^{-1}$ as a function of conversion percentage for each species in air and nitrogen are as shown in Fig. 5. Heating rates of $2.5,5,10$ and $15^{\circ} \mathrm{Cmin}^{-1}$ were used in these calculations. In nitrogen the curves generally exhibit an initially low activation energy at low conversion percentages, increasing to a plateau at $25-30 \%$ conversion, followed by a decrease at higher levels of conversion. The first step would correspond to the rapid degradation of hemicelluloses which might be expected due to their lower molecular weights and less-ordered character. The plateau region would be assigned to cellulose volatilization with the final stages associated with lignin degradation. The exception to this general form is once again S. tenerum, which even at low levels of conversion has an activation energy in excess of $100 \mathrm{~kJ} \mathrm{~mol}^{-1}$, with only a minimal increase to the plateau region. A. purpurescens also has an initial $E_{a}$ over $100 \mathrm{~kJ} \mathrm{~mol}^{-1}$, but more typically shows an increase of about $50 \mathrm{~kJ} \mathrm{~mol}^{-1}$ associated with cellulose degradation. A. virginicus, D. sericea and Eragrostis spp. have early $E_{a}$ values of $50-75 \mathrm{~kJ} \mathrm{~mol}^{-1}$, while I. cylindrica, $A$. 
stricta and $S$. junceus are found to have quite low activation energies at low levels of conversion. The former results might be indicative of lower levels of hemicellulose or hemicellulose with increased thermal resistance. The latter results would indicate a relatively low energy barrier associated with hemicellulose degradation. This is particularly notable for I. cylindrica which was also found to have the highest temperatures for this step.

The plateau regions assigned to cellulose degradation have differential activation energies and durations between species. The species with higher activation energies (A. stricta, I. cylindrica, A. purpurescens, and Eragrostis spp.) are generally also those for which the plateau region is longer ( $\sim 20-80 \%$ conversion). Among the remaining species, for which $E_{a}$ ranges from 134 to $97 \mathrm{~kJ} \mathrm{~mol}^{-1}$ for this degradation, the plateaus are somewhat shortened and begin to decrease at about $60 \%$ conversion. These differences could be related to variations in chemistry or physical properties of the cellulose components. Finally, it can be observed that $S$. tenerum continues to have very different properties from the other species with an abbreviated and variable region of cellulose degradation. In general, the activation energies compare well with the literature $[6,7]$.

As might be expected, the introduction of air results in dramatic changes in the mechanisms of thermal degradation as shown by the activation energy distributions. The activation energies in air are higher than in nitrogen, and considerably more variable. Notably, there is no plateau region as in nitrogen and in several cases $(A$. stricta, $S$. junceus and $S$. tenerum) there is an initial decrease in $E_{a}$ at low conversion levels. A. virginicus, I. cylindrica, S. tenerum, D. sericea, A. stricta and Eragrostis spp. exhibit generally increasing activation energies up to $60-70 \%$ conversion, perhaps indicative of competitive reactions with similar rates $[22,23]$. At the highest conversion levels $A$. purpurescens, I. cylindrica, D. sericea, and A. virginicus, have abrupt increases in $E_{a}$, while Eragrostis spp., A. stricta, $S$. tenerum and $S$. junceus decrease or remain relatively constant. These results would indicate that very different combustion chemistries may be at work between these species.

\section{Conclusions}

Forests dominated by longleaf pine ( $P$. palustris) are examples of ecosystems that are dependent on frequent, low-intensity fires. These forest types must burn every few years to maintain ecosystem integrity through the control of mid-story competition. Long-term studies have documented significant forest degradation even if the fire-return interval is extended by as little as 1-2 years. In longleaf pine forests, the fuels for the periodic fires include fallen pine needles and the grasses which comprise the understory [24]. Among the grasses evaluated in the current work, A. virginicus is the major species in the western part of the native longleaf range, while A. stricta is dominant in the east [25]. I. cylindrica and Eragrostis spp. are exotics, of which the former has received considerable attention because of its behavior in fires. The remaining species ( $D$. sericea, A. purpurescens, $S$. tenerum, and $S$. junceus) are all native to the longleaf range but not as generally distributed as $A$. virginicus and $A$. stricta. Given the importance of fire in the longleaf pine ecosystem, the role grasses play in the process and the occurrence of these species in association with longleaf pine, the current study was undertaken to examine the fundamental thermal properties of the grasses. Furthermore, this is the first report of such results for these species and as a consequence, the comparative literature is limited to the thermal analysis of other herbaceous material. Indeed, with the exception of the dominant species (A. virginicus and A. stricta) and $I$. cylindrica, due to its invasive nature, even the biological literature is limited for these grasses. There has also been recent interest in the inclusion of information such as ignition thresholds, combus- tion rates and transitions within combustion into physics-based fire models, representing an additional rationale for the current work.

To address these issues, thermogravimetric analyses have been performed. DTGA results show that the grasses differ in their degradation rates in both air and nitrogen. Varying levels of resolution in the DTGA results may be indicative of differences in chemical composition or structure. This is particularly evident for $S$. tenerum and S. junceus, in which atypical patterns of degradation are observed in air. The temperatures associated with the degradation events are consistently higher in nitrogen than in air. Among the most potentially interesting of these temperatures is $T_{\text {onset }(\mathrm{HC})}$, taken as the relative spontaneous ignition temperature [13]. From Fig. 3, it can be seen that I. cylindrica and Eragrostis spp. exhibit the highest levels for this term which would be consistent with the elevated temperatures that have been reported for fires when I. cylindrica is present. This trend continues for the $T_{\text {shoulder }}$ and $T_{\text {peak }}$ values, representing hemicellulose and cellulose degradation, respectively. As before I. cylindrica and Eragrostis spp. consistently exhibit the highest degradation temperatures. Both of these grasses are tropical in origin, with I. cylindrica native to south-east Asia and Eragrostis spp. from Africa. It might be speculated that the observed thermal behavior could impart advantages to these grasses in their native habitats. Among the other species, A. purpurescens, $A$. stricta and $A$. virgninicus are quite similar with respect to $T_{\text {shoulder }}$ and $T_{\text {peak }}$. The dominance of the latter two in the longleaf pine environment may be the result of such uniform thermal behavior. Complementary gravimetric data on the residue remaining at a given temperature also shows that I. cylindrica is degraded to the greatest extent. While distributions of activation energy over a wide range of conversions are reasonably uniform in nitrogen, in an oxidizing atmosphere the grasses appear to have quite different combustion mechanisms.

In summary, the current study represents initial work into the thermal properties of understory grasses that are of importance in the fire-dependent longleaf pine ecosystem. Subsequent work will relate this information to biological and ecological research on the behavior and management of these species.

\section{References}

[1] J.K. Kane, J.M. Varner, J.K. Hiers, The burning characteristics of southeastern oaks: discriminating fire facilitators from fire impeders, Forest Ecol. Manage. 256 (2008) 2039-2045.

[2] R.W. Fonda, Burning characteristics of needles from eight pine species, Forest Sci. 47 (2000) 390-396.

[3] R.H. White, D.R. Weise, K. Macks, A. Dibble, Cone calorimeter testing of vegetation: an update, in: Thirty-fifth International Conference on Fire Safety, Seventeenth International Conference on Thermal Insulation, Ninth International Conference on Electrical and Electronic Products, Columbus, OH, July 22-24, 2002.

[4] D.R. Weise, R.H. White, F.C. Beall, M. Ellinger, Use of the cone calorimeter to detect seasonal differences in selected combustion characteristics of ornamental vegetation, Int. J. Wildland Fire 14 (2005) 321-338.

[5] A.C. Dibble, R.H. White, P.K. Lebow, Combustion characteristics of north-eastern USA vegetation tested in the cone calorimeter: invasive versus non-invasive plants, Int. J. Wildland Fire 16 (2007) 426-443.

[6] S.-B. Lee, O. Fasina, TG-FTIR analysis of switchgrass pyrolysis, J. Anal. Appl. Pyrol. 86 (2009) 39-43.

[7] M. Jeguirim, G. Trouvé, Pyrolysis characteristics and kinetics of Arundo donax using thermogravimetric analysis, Bioresour. Technol. 100 (2009) 4026-4031.

[8] S. Munir, S.S. Dood, W. Nimmo, A.M. Cunliffe, B.M. Gibbs, Thermal analysis and devolatilization kinetics of cotton stalk, sugar cane bagasse, and shea meal under nitrogen and air atmospheres, Bioresour. Technol. 100 (2009) 1413-1418.

[9] F. Yao, O. Wu, Y. Lei, W. Guo, Y. Xu, Thermal decomposition kinetics of natural fibers: activation energy with dynamic thermogravimetric analysis, Polym. Degrad. Stabil. 93 (2008) 90-98.

[10] J. Leifeld, Calorimetric characterization of grass during its decomposition, J. Therm. Anal. Calorim. 93 (2008) 651-655.

[11] V. Leroy, D. Cancellieri, E. Leoni, J.-L. Rossi, Kinetic study of forest fuels by TGA: a model-free kinetic approach for the prediction of phenomena, Thermochim. Acta 497 (2010) 1-6.

[12] V. Leroy, D. Cancellieri, E. Leoni, Relation between forest fuels composition and energy emitted during their thermal degradation, J. Therm. Anal. Calorim. 96 (2009) 293-300. 
[13] S. Liodakis, T. Kakardakis, S. Tzortzakou, V. Tsapara, How to measure the particle ignitability of forest species by TG and LOI, Thermochim. Acta 477 (2008) 16-20.

[14] P. Rovira, C. Kurz-Besson, M.-M. Coûteaux, V.R. Vallejo, Changes in litter properties during decomposition: a study by differential thermogravimetry and scanning calorimetry, Soil Biol. Biochem. 40 (2008) 172-185.

[15] V. Leroy, D. Cancellieri, E. Leoni, Thermal degradation of ligno-cellulosic fuels: DSC and TGA studies, Thermochim. Acta 451 (2006) 131-138.

[16] R.F. Noss, E.T. LaRoe, J.M. Scott, Endangered ecosystems of the United States: a preliminary assessment of loss and degradation, USDA National Biological Service, Biological Report 28 (1995) 58 pp.

[17] M. Grønli, G. Várhegyi, C. Di Blasi, Thermogravimetric analysis and devolatilization kinetics of wood, Ind. Eng. Chem. Res. 41 (2002) 4201-4208.

[18] J.H. Flynn, L.A. Wall, A quick, direct method for the determination of activation energy from thermogravimetric data, Polym. Lett. 4 (1966) 323-328.

[19] American Society for Testing and Materials, E 1641-07, Standard test method for decomposition kinetics by thermogravimetry.
[20] C. Di Blasi, Combustion and gasification rates of lignocellulosic chars, Prog. Energy Combust. Sci. 35 (2009) 121-140.

[21] S. Jose, What research has found about cogongrass spread and control in the longleaf pine ecosystem, in: Proceedings of the Regional Cogongrass Conference: A Cogongrass Management Guide, November 7-8, Mobile, AL, USA, 2007, pp. 48-50.

[22] R.B. Prime, H.E. Bair, S. Vyazovkin, P.K. Gallagher, A. Riga, Thermogravimetric analysis (TGA), in: J.D. Menczel, R.B. Prime (Eds.), Thermal Analysis of Polymers, Fundamentals and Applications, Wiley, Hoboken, NJ, 2009, pp. 241-317.

[23] S. Vyazovkin, A unified approach to kinetic processing of nonisothermal data, Int. J. Chem. Kinet. 28 (1996) 95-101.

[24] K.W. Outcalt, The longleaf ecosystem of the South, Native Plants J. 1 (2000) 43-51.

[25] W.B. Boyer, Pinus palustris Mill., longleaf pine, in: R.M. Burns, B.H. Honkala (Eds.), Silvics of North America, Volume 1, Conifers, Agriculture Handbook 654, USDA-Forest Service, Washington, DC, 1990, pp. 405-412. 